\title{
Ethnicity, Stigma and Adherence to Antiretroviral Therapy (ART) among People Living with HIV/AIDS in Guangxi, China
}

\author{
Yuchen Mao*, Xiaoming Li, Shan Qiao, Yuejiao Zhou and Qun Zhao \\ Department of Health Promotion, Education and Behavior, University of South Carolina, Columbia, USA
}

\begin{abstract}
This study examines the impact of ethnicity and multiple types of HIV-related stigma on adherence to antiretroviral therapy (ART) among 2,146 people living with HIVIAIDS (PLWHA) in Guangxi, China who had initiated ART. The results of multiple binary logistic regressions indicate that those who had experienced enacted stigma tended to report lower adherence, while better adherence was associated with older age, being women and having a job. Ethnicity had a moderator effect on the association between internalized stigma and adherence since better adherence was associated with lower internalized stigma among participants in ethnic minority groups other than Zhuang. Our findings indicate that PLWHA of other ethnic minority groups could benefit from internalized stigma reduction interventions; PLWHA, overall, could benefit most from increased employment opportunities and acquisition of coping skills to mitigate the negative effects of enacted stigma.
\end{abstract}

Keywords: Ethnicity; Stigma; Adherence; Antiretroviral therapy; People living with HIV/AIDS

\section{Introduction}

In China, although people living with HIV/AIDS (PLWHA) only accounted for $0.037 \%$ of the total population by the end of 2014 , the prevalence is higher in some areas including Guangxi Autonomous Region (Guangxi). Meanwhile, the number of patients receiving antiretroviral therapy (ART) has been steadily increasing by a large margin each year. The percentage of PLWHA receiving ART increased from $52.1 \%$ in 2013 to $59.0 \%$ in 2014 and the percentage of PLWHA with CD4 counts $\leq 350 / \mathrm{mm}^{3}$ receiving ART increased from $81.9 \%$ in 2011 to $86.9 \%$ in 2014 (Ministry of Health China, 2015)

Most HIV patients have to receive lifelong ART, adherence to which is the practice of taking medications consistent with the prescribed treatment regimen, at the correct time interval and with the exact dose $[1,2]$. High levels of adherence are necessary to avoid development of resistant viruses and in turn abate HIV disease progression [3,4]. Many factors are associated with low adherence or non-adherence and have been documented by various studies [5-9]. For example, Genberg et al. [8] categorized barriers to ART adherence into 4 groups: medication and health concerns, stigma, family responsibilities and problems with schedule and routine. Okoror et al. [1] identified seeking alternative or traditional care, financial cost related to transportation among other things, side effects of medication, and stigma of being identified as HIV positive as factors for nonadherence. It is evident that HIV-related stigma has often been identified as one of the major barriers to adherence.

Some studies have focused specifically on the association of adherence to ART with stigma [1,10-12]. The findings, almost consistently, were that higher levels of stigma could result in lower levels of adherence. Some studies attempted to ascertain the associations of adherence with different types of stigma, including enacted, perceived and internalized stigma [13-16]. For example, Lyimo et al. [17] identified that perceived stigma compared to enact and internalized stigma could have greater impact on disclosure of HIV status which in turn affects adherence. However, the associations of different types of stigma with adherence are not yet well understood, especially in the resource-limited settings.

Ethnic affiliation can reflect cultural standards, social policies, and social structure pertinent to HIV [18]. Prior studies have identified that racial and ethnic minorities tended to have higher levels of stigma [19-22] and lower levels of adherence to ART [23-25]. For example, Kunstadter et al. [21] indicated that Yunnan Chinese as an ethnic minority group in north-western Thailand had the lowest level of HIVrelated knowledge compared to other ethnic groups, which could be associated with high stigma, low adherence and poor health outcomes. Shih [22] showed that ethnic minorities due to ethnic marginalization were labelled as being at high risk for HIV infection by the Chinese Center for Disease Control's public campaigns; thus their HIV-related stigma was exacerbated, and their adherence to HIV treatment was affected to a greater extent compared to the ethnic majority. The associations of ethnicity with stigma and adherence are still poorly understood in China, notwithstanding.

To date, the adherence to ART is suboptimal in China [26-28]. For example, in a study conducted among HIV-infected adults in Guangzhou, the percentage of participants who reported recent nonadherence was nearly 19\% [27]. Meanwhile, some previous studies indicated that HIV-related stigma could be higher in Asian countries including China [29-32]. Understanding how ethnicity, HIV-related stigma and adherence to ART interact with each other is important for more targeted interventions to improve adherence to ART and in turn health outcomes. Given that few studies have simultaneously focused on the roles of ethnicity and stigma in adherence to ART, the current study aims to examine the impact of ethnicity and multiple types of HIV-related stigma on adherence to ART among PLWHA in Guangxi, China, which is relatively resource-limited compared to the

*Corresponding author: Yuchen Mao, $\mathrm{PhD}$, University of South Carolina Department of Health Promotion, Education and Behavior, 915 Greene St. Discovery I Building, Suite 408, Columbia, SC 29208, USA, Tel: +19193485860 ; E-mail: mao7@mailbox.sc.edu

Received December 17, 2016; Accepted January 05, 2017; Published January 12,2017

Citation: Mao Y, Li X, Qiao S, Zhou Y, Zhao Q (2017) Ethnicity, Stigma and Adherence to Antiretroviral Therapy (ART) among People Living with HIVIAIDS in Guangxi, China. J AIDS Clin Res 8: 652. doi: 10.4172/2155-6113.1000652

Copyright: (c) 2017 Mao Y, et al. This is an open-access article distributed under the terms of the Creative Commons Attribution License, which permits unrestricted use, distribution, and reproduction in any medium, provided the original author and source are credited. 
economically-developed provinces in China. We hypothesize that there is a synergistic effect between HIV-related stigma and ethnic minority status on adherence.

\section{Methods}

\section{Study participants}

We conducted a cross-sectional study from 2012 to 2013 in Guangxi in Southwest China. Guangxi was ranked third among Chinese provinces in terms of HIV seropositive cases by the end of 2014 (Ministry of Health of China, 2015). With the assistance and collaboration of Guangxi Center for Disease Prevention and Control (Guangxi CDC), we randomly selected PLWHA from the top 12 sites ( 2 cities and 10 counties) with the largest number of HIV/AIDS cases (about 10\% of the reported cases at each site were selected).

The detailed sampling and survey procedures were reported elsewhere [33]. Briefly, the self-administered survey was conducted in offices of local CDC or HIV clinics where the participants received medical care. The interviewers were local CDC staff or health care workers in the HIV clinics who had received intensive training on research ethics and interview skills with PLWHA prior to the field data collection. The Institutional Review Boards at Wayne State University in the United States and Guangxi CDC in China reviewed and approved the research protocol. Among the 2,987 PLWHA completing the survey, a sample of 2,146 participants who had initiated ART was included in the current study.

\section{Measures}

\section{Background characteristics}

Participants were asked about individual and family characteristics including gender, age, ethnicity, marital status, place of original residence (local vs non-local), year of schooling, work status (fulltime job, part-time job and no job) and monthly household income in Chinese Yuan $(<1,000,1,000-1,999,2,000-2,999,3,000-3,999$, $4,000-4,999$, and $\geq 5,000)$. For data analysis in the current study, we categorized ethnicity into three groups: Han, Zhuang and Other. We also dichotomized marital status into married/cohabitating and not married/cohabitating and work status into having a full-time or parttime job and having no job. In addition, we combined the three highlevel income categories 3,000-3,999, 4,000-4,999 and $\geq 5,000$ into one group (" $\geq 3,000$ ") because of the relatively small number of respondents within each of these categories.

\section{HIV-related stigma}

HIV-related stigma was measured using modified items from the Berger HIV Stigma Scale that was previously validated in various studies [34]. Sixteen modified items were used to quantify the multiple domains of HIV-related stigma including enacted, perceived, and internalized stigma. Enacted stigma was measured using 2 items which asked participants whether they had experienced some stigmatized action (i.e., "I was denied jobs, school or social welfare because of HIV status", "My family members were excluded by others because of my HIV status"). If participants indicated they had experienced either of the stigmatized actions, their enacted stigma score was coded as "1" (Yes). Otherwise, their enacted stigma score was coded as " 0 " (No). Perceived stigma was measured using 6 items (e.g. "People with HIV/AIDS lose their jobs when their employers find out", "Most people believe a person with HIV/AIDS is disgusting") and internalized stigma was measured using 8 items (e.g. "I feel guilty because I have HIV", "Having HIV makes me feel that I am bad"). Responses for both perceived and internalized stigma items ranged from 1 (Strongly Disagree) to 4 (Strongly Agree). Reliability was satisfactory with Cronbach's $\alpha$ of 0.90 and 0.91 for perceived and internalized stigma, respectively.

\section{Adherence}

Four questions from the AIDS Clinical Trials Group Adherence Questionnaire were revised to gather information on adherence to ART in the current study [35]. Participants were asked whether they missed doses over the past 3 days, over the most recent weekend, and over the past month. The responses were then converted into percentage of prescribed doses and recoded into 1 ( $\geq 90 \%$ of prescribed doses) or 0 $(<90 \%)$. Whether participants ever missed a dose previously was also assessed and coded into 1 (yes) or 0 (no). An overall adherence score was calculated by summing scores of the four adherence behaviors. For the purpose of analysis, we dichotomized participants based on their overall adherence score into optimal (scored 4) and suboptimal adherence groups (scored less than 4).

\section{Data analysis}

Statistical analyses were conducted using SAS 9.4 (Statistical Analysis Software, Cary, NC). We first evaluated all types of stigma and the key socio-demographic characteristics in bivariate analyses for their associations with adherence. Specifically, single-predictor binary logistic regressions were conducted to examine the bivariate association between each potential predictor and adherence. Because the participants were nested in 12 sites, generalized estimating equation (GEE) approach was used to account for intraclass correlation among participants from the same site and performed using SAS GENMOD procedure with a "binomial" distribution, a "logit" link function and an "exchangeable" correlation structure. Thereafter, three multiple binary logistic regression models with the above-mentioned GEE approach were executed. The first model was designed to examine the main effects of ethnicity and multiple types of stigma on adherence. The second model was designed to examine how ethnicity and different types of stigma were related to adherence while controlling for key sociodemographic characteristics. The third model tested the hypothesized interaction of multiple types of stigma with ethnicity in forecasting the treatment adherence over and beyond the previous models.

\section{Results and Discussion}

\section{Sample characteristics}

The sample in the current analysis include 2,146 participants (1,316 males and 830 females) who reported being on ART at the time of survey. A majority of the participants reported a good medication adherence across the four adherence measures $(96.6 \%$ for adherence based on missing doses over the past 3 days, $96.1 \%$ for adherence based on missing doses over the past weekend, $93.3 \%$ for adherence based on missing doses over the past month and $66.3 \%$ never missed any dose). The sample's average age and year of schooling were 42.4 years $(\mathrm{SD}=12.5)$ and $7.01(\mathrm{SD}=3.02)$, respectively. More than twothirds $(68.5 \%)$ of the participants were of Han ethnicity, a little less than one-third (28.3\%) were of Zhuang ethnicity, and those from other ethnic minority groups accounted for less than 5\% (3.3\%). A majority of the participants were local (93.5\%), had a full-time or part-time job (73.6\%), had a monthly household income less than 2,000 yuan $(82.7 \%)$ and reported being married or in cohabitation (69.7\%). A majority of the participants (93.9\%) did not report experiencing enacted stigma, and on average, participants' perceived (mean $=2.60, \mathrm{SD}=0.58$ ) and internalized stigma scores (mean $=2.31, \mathrm{SD}=0.54$ ) were at the mid-point of the 4-point scale (Table 1). 
Citation: Mao Y, Li X, Qiao S, Zhou Y, Zhao Q (2017) Ethnicity, Stigma and Adherence to Antiretroviral Therapy (ART) among People Living with HIV/ AIDS in Guangxi, China. J AIDS Clin Res 8: 652. doi: 10.4172/2155-6113.1000652

Page 3 of 6

\begin{tabular}{|c|c|c|c|c|}
\hline & \multirow[t]{2}{*}{ Analytic sample $\mathrm{N}=\mathbf{2 1 4 6}$} & \multicolumn{2}{|c|}{ ART adherence group } & \multirow[t]{2}{*}{$\operatorname{cOR}(95 \% \mathrm{Cl})$} \\
\hline & & $\begin{array}{c}\text { Optimal } \\
1326(63.3 \%)\end{array}$ & $\begin{array}{l}\text { Suboptimal } \\
769(36.7 \%)\end{array}$ & \\
\hline \multicolumn{5}{|l|}{ HIV-related stigma } \\
\hline \multicolumn{5}{|l|}{ Enacted stigma } \\
\hline Yes & $124(6.1 \%)$ & $72(5.5 \%)$ & $52(7.2 \%)$ & $0.73^{\mathrm{a}}(0.60,0.94)$ \\
\hline No & $1894(93.9 \%)$ & $1228(94.5 \%)$ & $666(92.8 \%)$ & \\
\hline Perceived stigma & $2.60(0.58)$ & $2.60(0.57)$ & $2.59(0.60)$ & $1.03(0.90,1.17)$ \\
\hline Internalized stigma & $2.31(0.54)$ & $2.31(0.53)$ & $2.32(0.54)$ & $0.99(0.79,1.24)$ \\
\hline \multicolumn{5}{|c|}{ Sociodemographic factors } \\
\hline \multicolumn{5}{|l|}{ Gender } \\
\hline Male & $1316(61.3 \%)$ & $795(60.0 \%)$ & $488(63.5 \%)$ & \\
\hline Female & $830(38.7 \%)$ & $530(40.0 \%)$ & $281(36.5 \%)$ & $1.17(0.96-1.43)$ \\
\hline \multicolumn{5}{|l|}{ Ethnicity } \\
\hline Han & $1433(68.5 \%)$ & $901(68.1 \%)$ & $532(69.3 \%)$ & \\
\hline Zhuang & $591(28.3 \%)$ & $379(28.6 \%)$ & $212(27.6 \%)$ & $1.10(0.89,1.36)$ \\
\hline Others & $68(3.3 \%)$ & $44(2.2 \%)$ & $24(3.1 \%)$ & $1.07(0.67,1.71)$ \\
\hline \multicolumn{5}{|l|}{ Local } \\
\hline Yes & $1883(93.5 \%)$ & $1212(93.5 \%)$ & $671(93.6 \%)$ & $0.87(0.60,1.24)$ \\
\hline No & $130(6.5 \%)$ & $84(6.5 \%)$ & $46(6.4 \%)$ & \\
\hline \multicolumn{5}{|l|}{ Marital status } \\
\hline Married/cohabitation & $1426(69.7 \%)$ & $903(69.9 \%)$ & $523(69.4 \%)$ & $1.02(0.82,1.26)$ \\
\hline Other & $620(30.3 \%)$ & $389(30.1 \%)$ & $231(30.6 \%)$ & \\
\hline \multicolumn{5}{|l|}{ Work status } \\
\hline Full/part-time job & $1535(73.6 \%)$ & 985 (74.6\%) & $550(71.8 \%)$ & $1.13(0.83,1.55)$ \\
\hline No job & $551(26.4 \%)$ & $335(25.4 \%)$ & $216(28.2 \%)$ & \\
\hline \multicolumn{5}{|l|}{ Income (yuan) } \\
\hline $0-999$ & $1079(51.9 \%)$ & $703(53.4 \%)$ & $376(49.3 \%)$ & \\
\hline $1000-1999$ & $640(30.8 \%)$ & 394 (29.9\%) & $246(32.3 \%)$ & $0.90(0.74,1.09)$ \\
\hline 2000-2999 & $230(11.1 \%)$ & $143(10.9 \%)$ & $87(11.4 \%)$ & $0.96(0.71,1.30)$ \\
\hline$\geq 3000$ & $129(6.2 \%)$ & $76(5.8 \%)$ & $53(7.0 \%)$ & $0.80(0.48,1.33)$ \\
\hline Age & $42.37(12.47)$ & $43.31(12.82)$ & $40.72(11.66)$ & $1.02^{\mathrm{a}}(1.01,1.03)$ \\
\hline Year of schooling & $7.01(3.02)$ & $6.96(3.04)$ & $7.11(2.97)$ & $0.99(0.95,1.02)$ \\
\hline
\end{tabular}

ap $<0.05$, two-tailed

Table 1: Adherence in relation to stigma and sociodemographic characteristics.

\section{Bivariate analysis}

Table 1 also summarizes the bivariate associations of adherence with the key sociodemographic characteristics and stigma, which were measured by crude odds ratio (cOR) and its $95 \%$ confidence interval. Enacted stigma ( $\mathrm{cOR}=0.73,95 \% \mathrm{CI}: 0.60,0.94)$ tended to be negatively associated with adherence, which indicates that participants who did not experience enacted stigma were more likely to report better adherence. Meanwhile, age ( $\mathrm{COR}=1.02,95 \%$ CI: 1.01, 1.03) tended to be the only key sociodemographic characteristic associated with adherence, which means that older participants were more likely to have better adherence.

\section{Binary logistic regressions}

The results of the binary logistic regressions were shown in Table 2 and included adjusted odds ratio (aOR) with 95\% confidence interval for each predictor in the models. In the sample overall, the main effect of enacted stigma was detected since participants who did not experience enacted stigma tended to report better adherence (aOR=0.66, 95\% CI: 0.52, 0.85) (Model 1). Moreover, better adherence was associated with older age $(\mathrm{aOR}=1.02,95 \% \mathrm{CI}: 1.01,1.03)$, being women $(\mathrm{aOR}=1.16,95 \% \mathrm{CI}: 1.05,1.29)$, and having a full-time or part-time job (aOR=1.31, 95\% CI: 1.02, 1.68) (Model 2). When the multiplicative interaction terms between ethnicity and the three types of stigma were added (Model 3), the analyses revealed that compared to Han and Zhuang ethnic groups, adherence among other ethnic groups tended to be lower due to the existence of internalized stigma and negatively associated with internalized stigma $(\mathrm{aOR}=0.40,95 \% \mathrm{CI}$ : $0.17,0.96)$. Therefore, ethnicity was found to have a moderator effect on the association between internalized stigma and adherence.

\section{Conclusion}

The current study examined adherence to ART in relation to multiple types of stigma and ethnicity among PLWHA in Guangxi, China, and identified factors that could influence adherence. The main effect of enacted stigma, age, gender, and work status in adherence were found; meanwhile, ethnicity was found to have a moderator effect on the association between internalized stigma and adherence. The findings highlight certain trends that can inform future intervention efforts.

In our study, participants who experienced enacted stigma tended to report lower adherence, which is consistent with some previous studies conducted in Africa and South America indicating enacted stigma was a barrier to adherence while perceived stigma did not have a statistically significant association with adherence [36-40]. However, in some studies conducted in Europe and USA, perceived stigma was identified to be a barrier to adherence while enacted stigma did not have a statistically significant association with adherence $[4,41,42]$. The possible explanation for the finding in the current study might be that enacted stigma was related to avoidance of disclosing HIV status, which in turn led to poorer medical adherence. The mediation effect of 
Citation: Mao Y, Li X, Qiao S, Zhou Y, Zhao Q (2017) Ethnicity, Stigma and Adherence to Antiretroviral Therapy (ART) among People Living with HIV/ AIDS in Guangxi, China. J AIDS Clin Res 8: 652. doi: 10.4172/2155-6113.1000652

Page 4 of 6

\begin{tabular}{|c|c|c|c|}
\hline \multirow[b]{2}{*}{ Predictor } & \multicolumn{3}{|c|}{ Adherence } \\
\hline & $\begin{array}{c}\text { Model } 1 \\
\text { aOR }(95 \% \mathrm{CI})\end{array}$ & $\begin{array}{c}\text { Model } 2 \\
\text { aOR (95\% Cl) }\end{array}$ & $\begin{array}{c}\text { Model } 3 \\
\text { aOR (95\% CI) }\end{array}$ \\
\hline \multicolumn{4}{|l|}{ Main effect } \\
\hline Enacted stigma (yes $=1$ ) & $0.68^{a}(0.54,0.86)$ & $0.66^{a}(0.52,0.85)$ & $0.53^{a}(0.33,0.87)$ \\
\hline Perceived stigma & $1.04(0.77,1.40)$ & $1.06(0.76,1.49)$ & $1.08(0.71,1.65)$ \\
\hline Internalized stigma & $0.99(0.66,1.49)$ & $1.03(0.67,1.59)$ & $0.98(0.58,1.65)$ \\
\hline \multicolumn{4}{|l|}{ Moderator } \\
\hline \multicolumn{4}{|l|}{ Ethnicity } \\
\hline Han & Reference & Reference & Reference \\
\hline Zhuang & $1.12(0.90,1.40)$ & $1.08(0.85,1.37)$ & $0.74(0.34,1.61)$ \\
\hline Other & $1.05(0.65,1.69)$ & $1.00(0.65,1.54)$ & $4.40(0.71,27.29)$ \\
\hline \multicolumn{4}{|l|}{ Two-way interaction } \\
\hline \multicolumn{4}{|l|}{ Ethnicity*enacted stigma } \\
\hline Han*enacted stigma (yes=1) & & & Reference \\
\hline Han*enacted stigma $(\mathrm{no}=0)$ & & & Reference \\
\hline Zhuang*enacted stigma (yes=1) & & & $1.80(0.74,4.42)$ \\
\hline Zhuang ${ }^{*}$ enacted stigma $(\mathrm{no}=0)$ & & & Reference \\
\hline Other*enacted stigma (yes=1) & & & $2.00(0.31,12.66)$ \\
\hline Other ${ }^{*}$ enacted stigma $(\mathrm{no}=0)$ & & & Reference \\
\hline \multicolumn{4}{|l|}{ Ethnicity*perceived stigma } \\
\hline Han*perceived stigma & & & Reference \\
\hline Zhuang*perceived stigma & & & $0.90(0.53,1.52)$ \\
\hline Other*perceived stigma & & & $1.31(0.58,2.96)$ \\
\hline \multicolumn{4}{|l|}{ Ethnicity*internalized stigma } \\
\hline Haninternalized stigma & & & Reference \\
\hline Zhuang*internalized stigma & & & $1.30(0.68,2.50)$ \\
\hline Other*internalized stigma & & & $0.40^{\mathrm{a}}(0.17,0.96)$ \\
\hline \multicolumn{4}{|l|}{ Confounder variables } \\
\hline Gender (female=1) & & $1.16^{\mathrm{a}}(1.05,1.29)$ & $1.16^{\mathrm{a}}(1.05,1.29)$ \\
\hline Local (yes=1) & & $0.83(0.59,1.18)$ & $0.86(0.60,1.24)$ \\
\hline Married status (married=1) & & $1.02(0.81,1.28)$ & $1.01(0.81,1.26)$ \\
\hline Work status (full/part-time job=1) & & $1.31^{a}(1.02,1.68)$ & $1.33^{a}(1.04,1.70)$ \\
\hline \multicolumn{4}{|l|}{ Income } \\
\hline $0-999$ & & Reference & Reference \\
\hline $1,000-1,999$ & & $0.91(0.73,1.14)$ & $0.91(0.73,1.13)$ \\
\hline $2,000-2,999$ & & $0.92(0.69,1.23)$ & $0.94(0.70,1.26)$ \\
\hline$\geq 3,000$ & & $0.77(0.46,1.29)$ & $0.78(0.48,1.29)$ \\
\hline Age & & $1.02^{\mathrm{a}}(1.01,1.03)$ & $1.02^{\mathrm{a}}(1.01,1.03)$ \\
\hline Year of schooling & & $1.02(0.97,1.06)$ & $1.01(0.97,1.06)$ \\
\hline
\end{tabular}

ap $<0.05$, two-tailed.

Table 2: Results of the linear regression models predicting adherence.

HIV disclosure between stigma and adherence has yet to be explored through future research.

Our finding that internalized stigma was not related to adherence among the entire sample is contradictory to some previous studies which indicated that higher levels of internalized stigma were related to lower levels of adherence $[17,43,44]$. Some other studies, however, did not identify a statistically significant association of internalized stigma with adherence $[38,42,45]$. Our finding that internalized stigma was associated with adherence among participants in ethnic minority groups other than Zhuang might be explained by the synergy of stigma and ethnic minority status. HIV-positive patients who belonged to other ethnic minority groups felt further stigmatized and socially isolated, which in turn affects adherence. Future studies need to take ethnic minority groups' cultural standards and the social context into consideration to ascertain why internalized stigma affects adherence to ART among the groups.

A positive association between age and adherence is a finding consistent with some prior studies $[46,47]$. In a study on adherence among older HIV patients, the association is said to be likely due to their familiarity with medication usage for chronic diseases and increased awareness that treatment of HIV requires a high level of medication adherence or due to their advanced stage of the disease that makes them take medication with a high adherence [48]. Although in general older age has been associated with better adherence, we believe that maintaining a high level of adherence will be difficult for some older PLWHA due to various challenges in their life. The explanation for the association of having a job with better adherence is that those who had a job could have more stable living conditions or afford better medications than those who did not have a job.

There are limitations to be aware of in the current study. First, the number of participants in other ethnic groups was much smaller than that in Han and Zhuang ethnic groups, which might prevent the detection of ethnicity's moderator effects on the association between enacted or perceived stigma and adherence. Second, just two items were used to measure enacted stigma and may not truly capture the 
PLWHA's experience of stigma and discrimination. Third, this study was cross-sectional in design, and hence, causal relationships between HIV-related stigma and adherence cannot be inferred. Further research is warranted to identify causality between variables employing longitudinal study designs. Fourth, some potentially important correlates such as medication regimen and clinical factors, and accessibility to opportunity of care that may influence adherence were not incorporated into analysis. Incorporating these factors into analysis in future studies may help explain the associations of stigma and ethnicity with adherence identified in the current study. For example, different ethnic groups could have different access to opportunity of care, which might be the reason for the association of internalized stigma with adherence among other ethnic minority groups. Last, data gathered through the questionnaire may be subject to both recall and social desirability biases.

In spite of the limitations, our findings demonstrate the impact of multiple types of stigma on adherence to ART and in turn health outcomes among PLWHA in Guangxi, China. Our findings also demonstrate a moderator effect of ethnicity on the association between internalized stigma and adherence. Therefore, we conclude that PLWHA of other ethnic minority groups could benefit from interventions designed to help them manage internalized stigma; meanwhile, PLWHA, overall, could benefit most from increased employment opportunities, and acquisition of coping skills to mitigate the negative effects of enacted stigma.

\section{Acknowledgement}

The study was supported by the National Institute of Child and Human Development Grant \#R01HD074221 and National Natural Science Foundation of China General Program Grant \#NSF71673146. The article's contents are solely the responsibility of the authors and do not necessarily reflect the official view of $\mathrm{NICHD}$ or NSFC. The authors thank Guangxi CDC and the 12 recruitment sites for their support and the study participants for their courage in coming forward to participate in the study.

\section{References}

1. Okoror TA, Falade CO, Olorunlana A, Walker EM, Okareh OT (2013) Exploring the cultural context of HIV stigma on antiretroviral therapy adherence among people living with HIVIAIDS in southwest Nigeria. AIDS Patient Care STDS 27: $55-64$.

2. Wong TWK, Ussher J (2008) How do subjectively-constructed meanings ascribed to anti-HIV treatments affect treatment adherent practice? Qual Health Res 18: 458-468

3. Bangsberg DR (2006) Less than 95\% adherence to non-nucleoside reversetranscriptase inhibitor therapy can lead to viral suppression. Clin Infect Dis 43: 939-941.

4. Sumari-de Boer IM, Sprangers MAG, Prins JM, Nieuwkerk PT (2012) HIV stigma and depressive symptoms are related to adherence and virological response to antiretroviral treatment among immigrant and indigenous HIV infected patients. AIDS Behav 16: 1681-1689.

5. Gross R, Yip B, Lo Re V 3 ${ }^{\text {rd }}$, Wood E, Alexander CS, et al. (2006) A simple, dynamic measure of antiretroviral therapy adherence predicts failure to maintain HIV-1 suppression. J Infect Dis 194: 1108-1114.

6. de Bruin M, Hospers HJ, van Breukelen GJ, Kok G, Koevoets WM, et al. (2010) Electronic monitoring-based counselling to enhance adherence among HIVinfected patients: A randomized controlled trial. Health Psychol 29: 421-428.

7. Cambiano V, Lampe FC, Rodger AJ, Smith CJ, Geretti AM, et al. (2010) Longterm trends in adherence to antiretroviral therapy from start of HAART. AIDS 24: $1153-1162$

8. Genberg BL, Lee Y, Rogers WH, Wilson IB (2015) Four types of barriers to adherence of antiretroviral therapy are associated with decreased adherence over time. AIDS Behav 19: 85-92.

9. Silva JA, Dourado I, Brito AM, Silva CA (2015) Factors associated with nonadherence to antiretroviral therapy in adults with AIDS in the first six months of treatment in Salvador, Bahia State, Brazil. Cad Saude Publica 31: 11881198.

10. Stutterheim SE, Pryor JB, Bos AE, Hoogendijk R, Muris P, et al. (2009) HIVrelated stigma and psychological distress: The harmful effects of specific stigma manifestations in various social settings. AIDS 23: 2353-2357.

11. Li X, Huang L, Wang $H$, Fennie KP, He G, et al. (2011) Stigma mediates the relationship between self-efficacy, medication adherenceand quality of life among people living with HIVIAIDS in China. AIDS Patient Care STDS 25: 665671.

12. Taylor BS, Reyes E, Levine EA, Khan SZ, Garduno LS, et al. (2014) Patterns of geographic mobility predicts barriers to engagement in HIV care and antiretroviral treatment adherence. AIDS Patient Care STDS 28: 284-295.

13. Mahajan AP, Sayles JN, Patel VA, Remien RH, Sawires SR, et al. (2008) Stigma in the HIVIAIDS epidemic: A review of the literature and recommendations for the way forward. AIDS 22: S67-S79.

14. Dowshen N, Binns HJ, Garofalo R (2009) Experiences of HIV-related stigma among young men who have sex with men. AIDS Patient Care STDS 23: 371 376 .

15. Logie C, Gadalla TM (2009) Meta-analysis of health and demographic correlates of stigma towards people living with HIV. AIDS Care 21: 742-753.

16. Valenzuela C, Ugarte-Gil C, Paz J, Echevarria J, Gotuzzo E, et al. (2015) HIV stigma as a barrier to retention in HIV care at a general hospital in Lima, Peru: A case-control study. AIDS Behav 19: 235-245.

17. Lyimo RA, Stutterheim SE, Hospers HJ, de Glee T, van der Ven A, et al. (2014) Stigma, disclosure, coping and medication adherence among people living with HIVIAIDS in Northern Tanzania. AIDS Patient Care STDS 28: 98-105.

18. Pan SW, Li D, Carpiano RM, Spittal PM, Ruan Y (2016) Ethnicity and HIV epidemiology research in China. Lancet 388: 1052-1053.

19. Loutfy MR, Logie CH, Zhang Y, Blitz SL, Margolese SL, et al. (2012) Gender and ethnicity differences in HIV-related stigma experienced by people living with HIV in Ontario, Canada. PLoS One 7: e48168.

20. Earnshaw VA, Bogart LM, Dovidio JF, Williams DR (2013) Stigma and racial/ ethnic HIV disparities: Moving toward resilience. Am Psychol 68: 225-236.

21. Kunstadter $P$ (2013) Ethnicity, socioeconomic characteristics and knowledge beliefs and attitudes about HIV among Yunanese Chinese, Hmong, Lahu and Northern Thai in a north-western Thailand border district. Cult Health Sex 15: S383-S400.

22. Shih $E$ (2013) Health and rights at the margins: Human trafficking and HIV AIDS amongst Jingpo ethnic communities in Ruili City, China. Anti-Trafficking Review 2: 119-136.

23. Lazo M, Gange SJ, Wilson TE, Anastos K, Ostrow K, et al. (2007) Patterns and predictors of changes in adherence to highly active antiretroviral therapy: Longitudinal study of men and women. Clin Infect Dis 45: 1377-1385.

24. Halkitis P, Palamar J, Mukherjee P (2008) Analysis of HIV medication adherence in relation to person and treatment characteristics using hierarchical linear modeling. AIDS Patient Care STDS 22: 323-335

25. Simoni JM, Huh D, Wilson IB, Shen J, Goggin K, et al. (2012) Racial/Ethnic disparities in ART adherence in the United States: Findings from the MACH14 study. J Acquir Immune Defic Syndr 60: 466-472.

26. Xing H, Wang X, Liao L, Ma Y, Su B, et al. (2013) Incidence and associated factors of HIV drug resistance in Chinese HIV-infected patients receiving antiretroviral treatment. PLoS One 8: e62408.

27. Muessig KE, McLaughlin MM, Nie JM (2014) Suboptimal antiretroviral therapy adherence among HIV-infected adults in Guangzhou, China. AIDS Care 26 988-995.

28. Yan H, Yang H, Li J, Wei C, Xu J, et al. (2014) Emerging disparity in HIVIAIDS disease progression and mortality for men who have sex with men, Jiangsu Province, China. AIDS Behav 18: S5-S10.

29. Rao D, Feldman BJ, Fredericksen RJ, Crane PK, Simoni JM, et al. (2012) A structural equation model of HIV-related stigma, depressive symptoms and medication adherence. AIDS Behav 16: 711-716.

30. Li L, Lee SJ, Thammawijaya P, Jiraphongsa C, Rotheram-Borus MJ (2009) Stigma, social support and depression among people living with HIV in Thailand. AIDS Care 21: 1007-1013. 
Citation: Mao Y, Li X, Qiao S, Zhou Y, Zhao Q (2017) Ethnicity, Stigma and Adherence to Antiretroviral Therapy (ART) among People Living with HIV/ AIDS in Guangxi, China. J AIDS Clin Res 8: 652. doi: 10.4172/2155-6113.1000652

Page 6 of 6

31. Feng $Y, W u Z$, Detels $R$ (2010) Evolution of men who have sex with men community and experienced stigma among men who have sex with men in Chengdu, China. J Acquir Immune Defic Syndr 53: S98-S103.

32. Abdullah T, Brown TL (2011) Mental illness stigma and ethnocultural beliefs, values and norms: An integrative review. Clin Psychol Rev 31: 934-948.

33. Qiao S, Li X, Zhou Y, Shen Z, Tang Z, et al. (2015) Factors influencing the decision-making of parental HIV disclosure: A socio-ecological approach. AIDS 29: S25-S34.

34. Berger BE, Ferrans CE, Lashley FR (2001) Measuring stigma in people with HIV: Psychometric assessment of the HIV stigma scale. Res Nurs Health 24: 518-529.

35. Reynolds NR, Sun J, Nagaraja HN, Gifford AL, Wu AW, et al. (2007) Optimizing measurement of self-reported adherence with the ACTG adherence questionnaire: A cross-protocol analysis. J Acquir Immune Defic Syndr 46: 402 409

36. Carlucci JG, Kamanga A, Sheneberger R, Shepherd BE, Jenkins CA, et al. (2008) Predictors of adherence to antiretroviral therapy in rural Zambia. J Acquir Immune Defic Syndr 47: 615-622.

37. Watt MH (2008) Understanding patients' adherence to antiretroviral therapy: A mixed-methods study in Arusha, Tanzania. University of North Carolina at Chapel Hill; Chapel Hill, NC.

38. Peltzer K, Friend-du Preez N, Ramlagan Sanderson J (2010) Antiretrovira treatment adherence among HIV patients in KwaZulu-Natal, South Africa. BMC Public Health 10: 111.

39. Boyer S, Clerc I, Bonono CR, Marcellin F, Bilé PC, et al. (2011) Non-adherence to antiretroviral treatment and unplanned treatment interruption among people living with HIVIAIDS in Cameroon: Individual and healthcare supply-related factors. Soc Sci Med 72: 1383-1392.
40. Franke MF, Murray MB, Munoz M, Diaz HS, Sebastian JL, et al. (2011) Food insufficiency is a risk factor for suboptimal antiretroviral therapy adherence among HIV-infected adults in urban Peru. AIDS Behav 15: 1483-1489.

41. Colbert AM (2007) Functional health literacy, medication-taking self-efficacy and HIV medication adherence. University of Pittsburgh, Pittsburgh, PA

42. Wolitski RJ, Pals SL, Kidder DP, Courtenay-Quirk C, Holtgrave DR (2009) The effects of HIV stigma on health, disclosure of HIV status and risk behavior of homeless and unstably housed persons living with HIV. AIDS Behav 13: 1222 1232.

43. Diiorio C, McCarty F, Depadilla L, Resnicow K, Holstad MM, et al. (2009) Adherence to antiretroviral medication regimens: A test of a psychosocial model. AIDS Behav 13: 10-22.

44. Mo PK, Mak WW (2009) Intentionality of medication non-adherence among individuals living with HIVIAIDS in Hong Kong. AIDS Care 21: 785-795.

45. Kalichman SC, Pope H, White D, Cherry C, Amaral CM, et al. (2008) The association between health literacy and HIV treatment adherence: Furthe evidence from objectively measured medication adherence. J Int Assoc Physicians AIDS Care 7: 317-323.

46. Hinkin CH, Hardy DJ, Mason KI, Castellon SA, Durvasula RS, et al. (2004) Medication adherence in HIV-infected adults: Effect of patient age, cognitive status and substance abuse. AIDS 18: S19-S25.

47. Barclay TR, Hinkin $\mathrm{CH}$, Castellon SA, Mason KI, Reinhard MJ, et al. (2007) Age-associated predictors of medication adherence in HIV-positive adults: Health beliefs, self-efficacy and neurocognitive status. Health Psychol 26: 4049.

48. Burgess MJ, Zeuli JD, Kasten MJ (2015) Management of HIVIAIDS in olde patients-drug/drug interactions and adherence to antiretroviral therapy. HIV AIDS 7: 251-264 